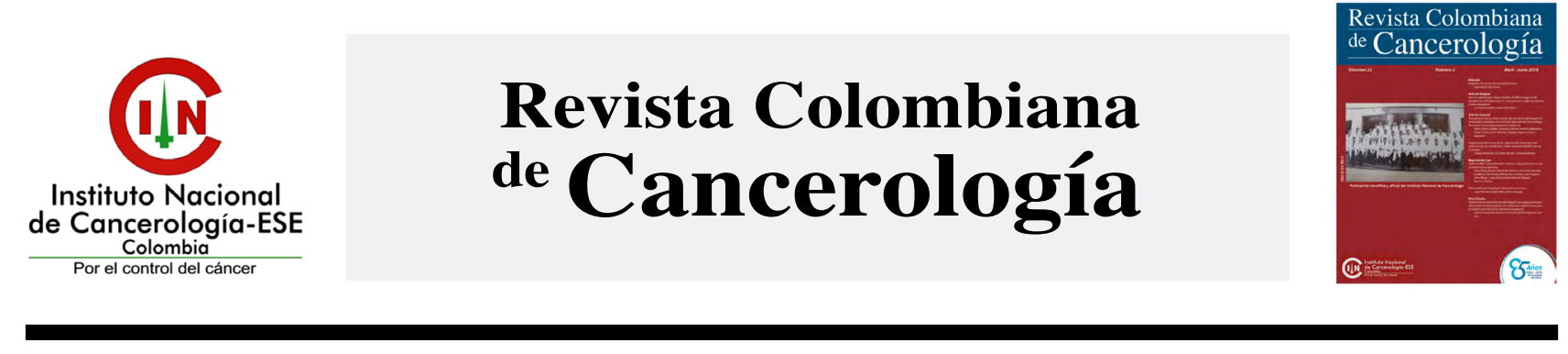

\title{
El uso off label de medicamento: ¿buena o mala práctica?
}

\author{
The use of the medicinal off label: Good or bad practice?
}

\section{De la definición}

En el marco de la medicina gestionada, el uso y autorización para el pago de medicamentos debe realizarse en el contexto de las buenas prácticas clínicas. En la actualidad, uno de los elementos críticos que suele clasificarse como de mala práctica es el uso de medicamentos sin la indicación aprobada por los organismos regulatorios. El término más conocido para el uso de medicamentos sin indicación es el de off label; en un intento por castellanizar el término, se le ha denominado también uso fuera de indicación, indicación no habitual, no oficial, no autorizada, no aprobada, uso alternativo o uso desvirtuado, y para el caso de Colombia se acuñó el término Uso No Indicado en el Registro Sanitario (UNIRS). Todos estos conceptos tienen en común la información existente en el registro sanitario: indicación, dosis, vías de administración y población. Por lo tanto, el uso off label (de ahora en adelante UNIRS) de un medicamento varía dependiendo de las condiciones bajo las cuales fue aprobada su comercialización en cada país (1).

En el caso de Colombia existen algunos problemas al aplicar estrictamente esta definición, ya que la dosis no está incluida en la mayoría de los registros sanitarios y la indicación terapéutica en ocasiones se confunde con el efecto farmacológico y no se concreta a una indicación en particular o puede variar de un registro a otro. A continuación, algunos ejemplos:

Para la furosemida (tabletas o solución inyectable) existen 18 registros sanitarios vigentes. De estos, 6 presentan la indicación como diurético, lo que corresponde a un efecto farmacológico y no a una indicación. Los 12 restantes tienen la autorización de diurético, antihipertensivo (uno de ellos utiliza la palabra antihipertensor), lo cual corresponde al efecto farmacológico y a la indicación. Sin embargo, la indicación para el manejo de la falla cardiaca no aparece en ningún registro sanitario, por lo que en Colombia el uso de furosemida en esta condición sería considerada UNIRS (2).

Para el caso de los corticoides administrados por vía oral o parenteral se toma el caso de la metilprednisolona para la cual existen 13 registros sanitarios vigentes. En todos ellos la indicación aprobada es terapia corticoide, con lo que se abre un abanico de posibilidades para su uso (2). Finalmente, aunque hay más ejemplos, para el ondansetrón se encontraron 22 registros sanitarios vigentes. En todos está presente la indicación para el tratamiento de las náuseas y vómitos asociados a quimioterapia citotóxica (10 de ellos de manera exclusiva), en 9 se incluye además la indicación de náuseas y vómito postoperatorio y en 3 también se incluye la indicación en náuseas y vómitos asociados a gastroenteritis viral o bacteriana (2). Para este último caso, el Ministerio de Salud en el numeral 9 del artículo 10 de la resolución 1885 de 2018 ya prevé una solución de este problema.

\section{De las consecuencias}

No es conveniente calificar el UNIRS como bueno o malo, pues todo depende de las condiciones clínicas del paciente. En el artículo publicado en este número de la Revista Colombiana de Cancerología titulado "Análisis del uso de fármacos fuera de indicación autorizada en hematología y oncología" los autores analizan las solicitudes de medicamentos en condiciones distintas a las incluidas en su ficha técnica, así como los resultados obtenidos por el Servicio de Oncología y Hematología en un hospital de segundo nivel en Murcia, España. En este artículo se explican las razones por las cuales se utilizan los medicamentos en condiciones off label y relacionan las consecuencias clínicas del uso. Para el caso de pediatría, ya se han elaborado algunas propuestas de su uso dado que muchos de los medicamentos que se utilizan en oncología no tienen indicación para pediatría y han sido efectivos en el tratamiento (3). Otros desarrollos se han publicado como para las gestantes (4). El reto no es prohibir o calificar de mala práctica, sino conocer exactamente en qué condiciones se están utilizando, teniendo como principal objetivo la sobrevida o la mejoría de la calidad de vida del paciente sin olvidar las consecuencias económicas (gasto en salud) y sociales (acceso) (1). Las consecuencias adversas de los UNIRS corresponden a una falta de respuesta terapéutica, que en el caso del cáncer puede afectar emocionalmente al paciente y su familia, y a reacciones adversas en condiciones de pobre eficacia (balance negativo beneficio/riesgo) y desperdicio de recursos económicos por parte del sistema de salud. En el campo de la ética se debe contemplar el hecho de que en los casos donde no existe evidencia la persona será sujeto de experimentación y se debe contar con el consentimiento informado por parte del paciente o sus cuidadores.

\section{De las propuestas}

Desde el ámbito regulatorio es necesario aclarar que el registro sanitario se le concede a un privado, por lo tanto, en Colombia, 
ni el Ministerio de Salud ni el INVIMA podrán alterar este documento para adicionar o modificar indicaciones en las cuales haya evidencia suficiente de su balance beneficio/riesgo. Por tal razón, en Colombia ya arrancó un proceso para documentar todos los usos considerados UNIRS, con el fin de evaluar si la evidencia es suficiente y así financiar con recursos del Estado (5). En aquellos casos con información insuficiente, el Ministerio de Salud junto con el ahora Ministerio de Ciencia y Tecnología deberían apoyar el desarrollo de estudios que ayuden a cerrar esta brecha de conocimiento.

Desde la práctica clínica se debe consultar siempre con el servicio farmacéutico cuando haya dudas, especialmente en lo relacionado con los cambios en la vía de administración. El UNIRS siempre debe ir precedido de información clara y suficiente al paciente o sus cuidadores y la firma del consentimiento informado. Finalmente, se debe considerar utilizar un medicamento en UNIRS cuando:

- No existen tratamientos efectivos o disponibles en una presentación farmacéutica que permita su uso por una determinada vía o ya se han agotado las alternativas terapéuticas existentes.

- La condición del paciente amenaza la vida o deteriora su calidad de vida de manera importante.

- Existe evidencia en la literatura científica, especialmente si los estudios son de buena calidad. En caso de que no existan estudios o los que haya disponibles sean de mala calidad se considerará uso compasivo.

En conclusión, existen brechas de conocimiento en poblaciones especiales (niños, gestantes y lactantes) que favorecen el uso de medicamentos en condiciones de UNIRS, lo cual no lo hace ni bueno ni malo, solo que no hay información suficiente. En la práctica clínica es necesario plantearse discusiones éticas de condiciones UNIRS con el fin de no generar falsas expectativas o exponer a un riesgo innecesario a los pacientes como también considerar las posibles implicaciones de esta práctica.

José Julián López G. Director Centro de Información Medicamentos de la Universidad Nacional (CIMUN), Facultad de Ciencias, Sede Bogotá, Universidad Nacional de Colombia

\section{Bibliografía}

1. Vanegas EP, Acosta AP, Vaca González C, López Gutiérrez JJ, Pineda LA, Guzmán HJ, et al. Propuesta de un modelo de gestión de medicamentos en indicaciones no registradas en Colombia. Rev Panam Salud Publica. 2016;39(5):274-80.

2. Base de datos de registros sanitarios, INVIMA. [Consultado en febrero 16 de 2020]. Disponible en: http://consultaregistro. invima.gov.co:8082/Consultas/consultas/consreg_encabcum. jsp

3. Committee On Drugs. Policy statement: Off-Label Use of Drugs in Children. Pediatrics. 2014, 133(3):563-67. https:// doi.org/10.1542/peds.2013-4060
4. Rayburn WF, Farmer KC. Off-label prescribing during pregnancy. Obstet Gynecol Clin North Am. 1997;24(3):471-8. https:// doi.org/10.1016/S0889-8545(05)70317-X

5. Documento Ministerio de Salud. [Consultado en febrero $16 \mathrm{de}$ 2020]. Disponible en: http://acho.com.co/acho/wp-content/ uploads/2018/02/MIPRES.pdf 